\title{
Mosquito Economics in Laboratory: A Retrospective Study in a Tertiary Care Hospital in India
}

\author{
Rateesh Sareen*, Menka Kapil and G N Gupta \\ Department of Pathology, Santokba Durlabhji Memorial Hospital \& Research center, Jaipur. India
}

\begin{abstract}
Background: Malaria, Dengue and Chikungunya are the major mosquito transmitted febrile illness in India. The retrospective study shows the three year trends in the laboratory testing for these diseases. These mosquito borne fever occur in the post monsoon period from late August till October every year.

Methods: We collected data from test ordered for three mosquito borne diseases for past three years from laboratory software. Descriptive statistical analysis was done.

Result: The total tests ordered for Malaria in the three year period were 4224, 5433 \& 2360 for the year 2015-17, for Dengue 3978, 5957 \& 2360 and for Chikungunya 258, 2525 \& 170 respectively. The percentage positivity for malaria over three year period was $1.78 \%$ for 2015 , $2.04 \%$ for 2016 and $1.99 \%$ for 2017. For Dengue it was $50.25 \%$ for $2015,30.6 \%$ for 2016 and $14.76 \%$ for 2017. Chikungunya had higher percentage positivity in 2016 which was $28.67 \%, 13.18 \%$ in 2015 and $12.94 \%$ in 2017 . The demand for tests was maximum in post monsoon period from September till October for the entire three vectors borne illness every year.

Conclusion: The magnitude of increased workload on diagnostic facilities poses a challenge to developing countries. The study will enable the policy makers in taking rationale scientific decisions to issues of sanitation, cleanliness and hygiene in general, population and also on manpower management in diagnostic services so as to deliver quality health care facilities in the need of hour.
\end{abstract}

\section{Keywords: Vector Borne Disease, Seasonal Trend}

\section{Introduction}

Vector -borne diseases are illness caused by pathogens and parasites in human population. In India vector borne diseases such as Malaria, Dengue and Chikungunya present as febrile illness and are leading cause of morbidity. On one hand our country suffers from burden of this vector borne disease which is related to sanitation, hygiene issues and availability of safe drinking water on the other hand there is emergence of non communicable disease linked to life style changes [1]. We have to make a balance in allocation of resources among diseases of developing and developed country. Half of India's disease burden in any financial year is attributed to these seasonal diseases [2].

In India there is wide distribution of anopheline vectors but they transmit primarily two Plasmodia species named P. Vivax and P. Falciparum. According to the World Health Organization (WHO) India alone contributed to $76 \%$ cases of malaria from south East Asia in 2014 [3]. The world malaria report published in 2014 showed that in India $22 \%$ population lives in high transmission areas ( $>1$ case per 1000 population), $67 \%$ live in low transmission areas (0-1 case per 1000 population) and $11 \%$ live in malaria free areas (zero case) [4]. Malaria comprises the chunk of vector borne disease; according to the Directorate of the National Vector Borne Disease Control Program me (NVBDCP), about $95 \%$ of our population resides in malaria endemic zone [5].

Dengue fever is a mosquito borne viral disease with four virus serotypes (DEN-1, DEN-2, DEN-3 and DEN-4) that are present in Asia, Africa and America $[6,7]$. It has become a significant health problem due to expanding geographic distribution with climate change and gradual evolution from an epidemic with long year's interval into an epidemic with seasonal trend $[8$, 9]. Vector development and survival rates are affected by temperature, precipitation and humidity although the associations of environmental factors are not consistently described in literature $[10,11]$.

Chikungunya on the other hand is a flavi viral infection transmitted to humans by Aedis aegypti [12]. It is relatively unknown in Indian population till it appeared in epidemic propotions in 2006. The word Chikungunya originated from the word Kungunyala (meaning that which bends up) as the patients suffering from Chikungunya develop a stooped posture because of severe arthritis affecting feet, ankles, hands and wrists [13]. 
The entire three vector borne viral fevers have high incidence in late monsoon where they pose a major health problem. There is paucity of data on the economic burden on the household and the expected cost of illness. This paper attempts to retrospectively analyze the seasonal and yearly trends in the laboratory workload due to these vector borne diseases so that effective preventive as well as curative measures can be taken to save precious lives.

\section{Materials and Methods}

We conducted a retrospective study in the department of Pathology \& Transfusion Medicine at our center over the period of two and a half years from 2015 till September 2017 to analyze the trend in testing for these mosquito transmitted fever. The study population were all patients who came to the department for any of the three vector borne febrile illness; Malaria, Dengue and Chikungunya. The data was collected from the laboratory software and descriptive statistics was applied. Patients who had undergone twice testing for the specific disease were considered as single case and no duplication of patients was done in the study.

\section{Result}

The retrospective study for three vector borne disease - Malaria, Dengue and Chikungunya was done in our department. The test ordered for malaria, dengue and chikungunya in the year 2015 were 4224, 3978 and 258 respectively (Table-1, Fig-1). There was increase in the number of tests ordered in 2016 where the figures for three vectors borne disease stood at 5433, 5957 and 2525 respectively (Fig-2). In 2017, till September the test numbers stood at 2360, 2588 and 170 respectively (Fig3 ). The percentage positivity for malaria over three years was $1.78 \%$ in $2015,2.04 \%$ in 2016 and $1.99 \%$ in 2017 (Table-1). The positivity for dengue was $50.25 \%$ in 2015 , $30.60 \%$ in 2016 and $14.76 \%$ in 2017 (Table-1). Similarly for chikungunya the percentage positivity was $13.18 \%$, $28.67 \%$ and $12.94 \%$ in three consecutive years under study (Table-1). The number of test ordered showed a steep increase in August month rising to peak in September and October and then falling in November (Figure-4, 5\&6). More than $50 \%$ of the tests ordered for specific vector borne disease were recorded in the three month span from August to October (Table-2, $3 \& 4$ ).

Table 1: Data of Vector borne disease 2015-2017.

\begin{tabular}{|c|c|c|c|}
\hline \multicolumn{4}{|c|}{ Malaria cases 2015-September 2017} \\
\hline & Total cases & Positive cases & Percentage \\
\hline Year 2015 & 4224 & 75 & 1.78 \\
\hline Year 2016 & 5433 & 111 & 2.04 \\
\hline Year 2017 & 2360 & 47 & 1.99 \\
\hline \multicolumn{4}{|c|}{ Dengue cases 2015-September 2017} \\
\hline & Total cases & Positive cases & Percentage \\
\hline Year 2015 & 3978 & 1999 & 50.25 \\
\hline Year 2016 & 5957 & 1823 & 30.6 \\
\hline Year 2017 & 2588 & 382 & 14.76 \\
\hline \multicolumn{4}{|c|}{ Chikungunya Cases 2015-September 2017} \\
\hline & Total cases & Positive cases & Percentage \\
\hline Year 2015 & 258 & 34 & 13.18 \\
\hline Year 2016 & 2525 & 724 & 28.67 \\
\hline Year 2017 & 170 & 22 & 12.94 \\
\hline
\end{tabular}

Table 2: Seasonal trend of malaria over 3 years.

\begin{tabular}{|l|c|c|c|} 
& $\mathbf{2 0 1 5}$ & $\mathbf{2 0 1 6}$ & $\mathbf{2 0 1 7}$ \\
\hline Jan & 149 & 129 & 92 \\
\hline Feb & 178 & 134 & 203 \\
\hline March & 166 & 195 & 182 \\
\hline April & 186 & 182 & 218 \\
\hline May & 198 & 209 & 197 \\
\hline June & 192 & 187 & 258 \\
\hline July & 214 & 259 & 491 \\
\hline Aug & 428 & 569 & 600 \\
\hline Sep & 873 & 1564 & \\
\hline
\end{tabular}




\begin{tabular}{|l|c|c|c|} 
& $\mathbf{2 0 1 5}$ & $\mathbf{2 0 1 6}$ & $\mathbf{2 0 1 7}$ \\
\hline Oct & 890 & 1226 & \\
\hline Nov & 461 & 548 & 231 \\
\hline Dec & 289 & $\mathbf{5 4 3 3}$ & $\mathbf{2 3 6 0}$ \\
\hline Total & $\mathbf{4 2 2 4}$ & \\
\hline
\end{tabular}

Table 3: Seasonal trend of Dengue over 3 years.

\begin{tabular}{|l|c|c|c|}
\hline & $\mathbf{2 0 1 5}$ & $\mathbf{2 0 1 6}$ & $\mathbf{2 0 1 7}$ \\
\hline Jan & 65 & 50 & 99 \\
\hline March & 36 & 31 & 52 \\
\hline April & 41 & 31 & 92 \\
\hline May & 35 & 71 & 96 \\
\hline June & 53 & 114 & 146 \\
\hline July & 45 & 78 & 132 \\
\hline Aug & 104 & 135 & 690 \\
\hline Sep & 393 & 498 & 1083 \\
\hline Oct & 1298 & 2130 & \\
\hline Nov & 1100 & 1890 & 27 \\
\hline Dec & 564 & 727 & $\mathbf{2 5 8 8}$ \\
\hline Total & 244 & $\mathbf{5 9 5 7}$ & \\
\hline
\end{tabular}

Table 4: Seasonal trend of Chikungunya over 3 years.

\begin{tabular}{|l|c|c|c|}
\hline & $\mathbf{2 0 1 5}$ & $\mathbf{2 0 1 6}$ & $\mathbf{2 0 1 7}$ \\
\hline Jan & 16 & 7 & 41 \\
\hline Feb & 11 & 5 & 11 \\
\hline March & 23 & 13 & 18 \\
\hline May & 17 & 8 & 14 \\
\hline June & 14 & 10 & 15 \\
\hline July & 7 & 7 & 13 \\
\hline Aug & 16 & 42 & 27 \\
\hline Sep & 27 & 890 & 23 \\
\hline Oct & 45 & 945 & \\
\hline Nov & 37 & 456 & \\
\hline Dec & 25 & 131 & \\
\hline Total & 20 & $\mathbf{2 5 2 5}$ & \\
\hline
\end{tabular}

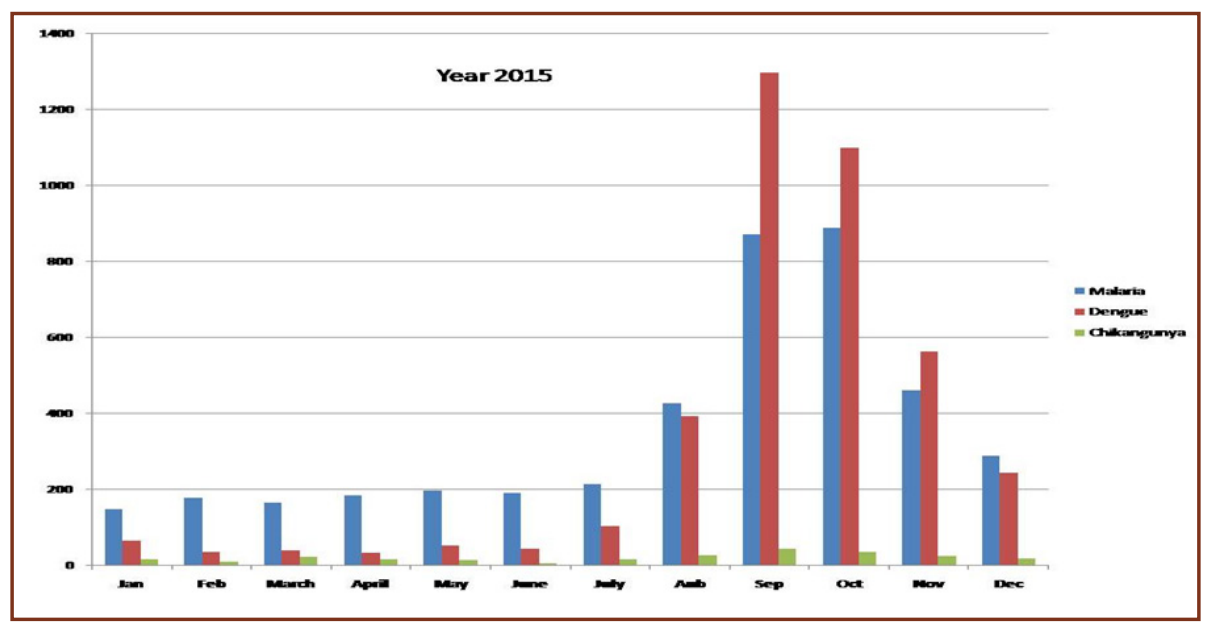

Fig.1: Monthly testing trend of three vector borne illness in 2015. 


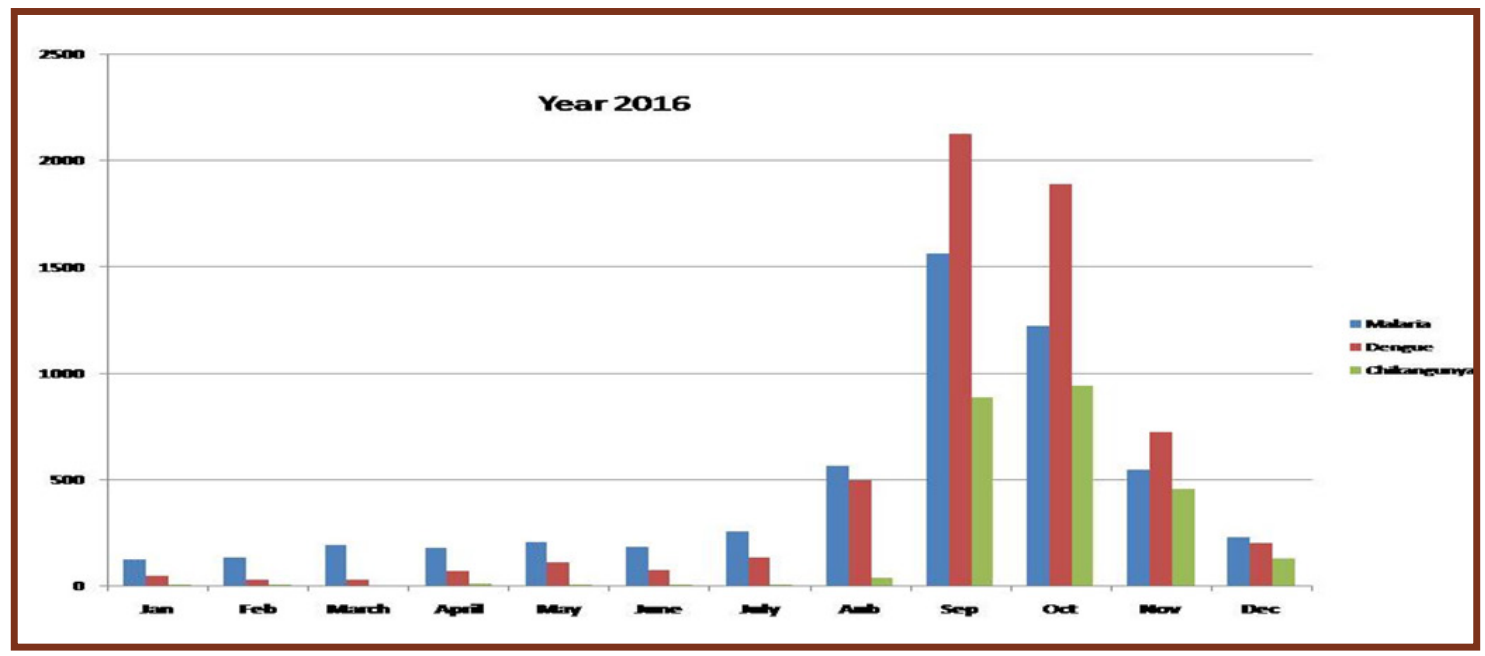

Fig. 2: Monthly testing trend of three vector borne illness in 2016.

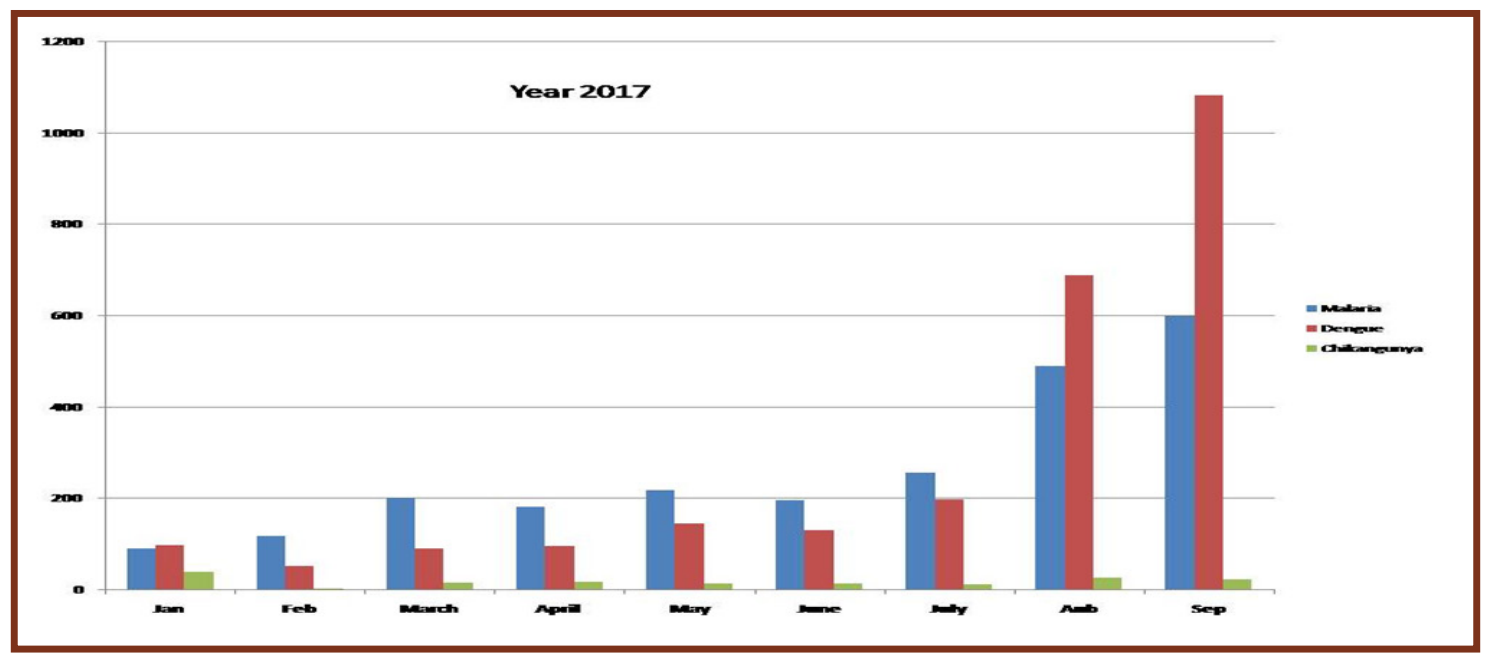

Fig.3: Monthly testing trend of three vector borne illness in 2017.

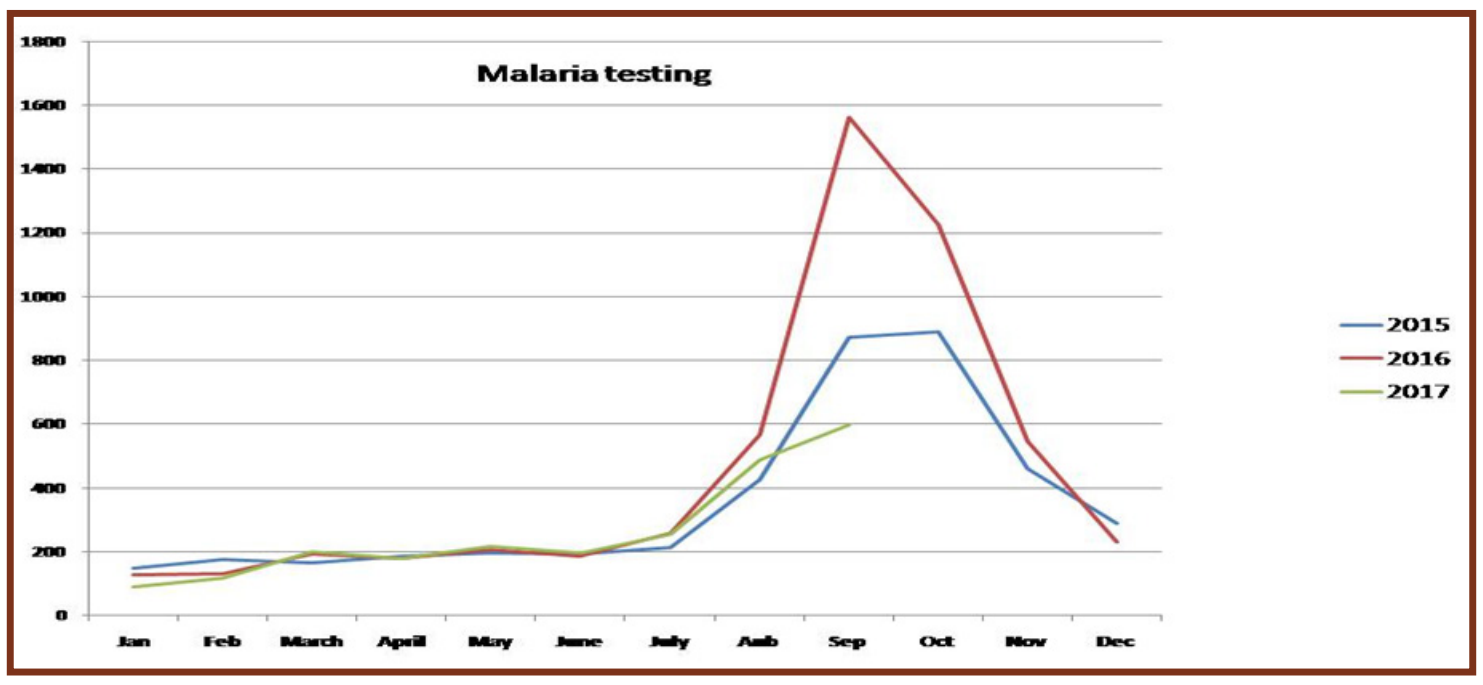

Fig. 4: Malaria testing yearly trend.

Annals of Advanced Medical Science, Vol. 1; Issue 1, October-December 2017 


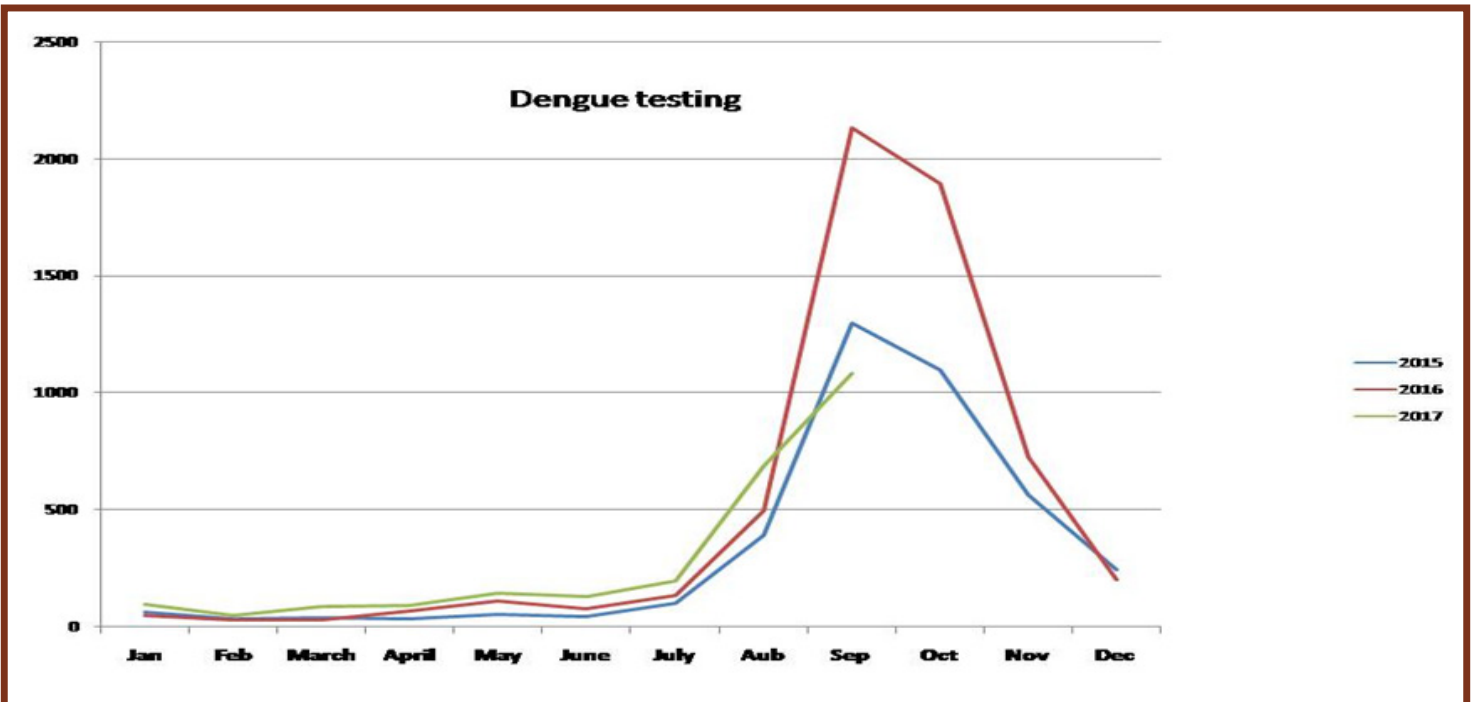

Fig. 5: Dengue testing yearly trend.

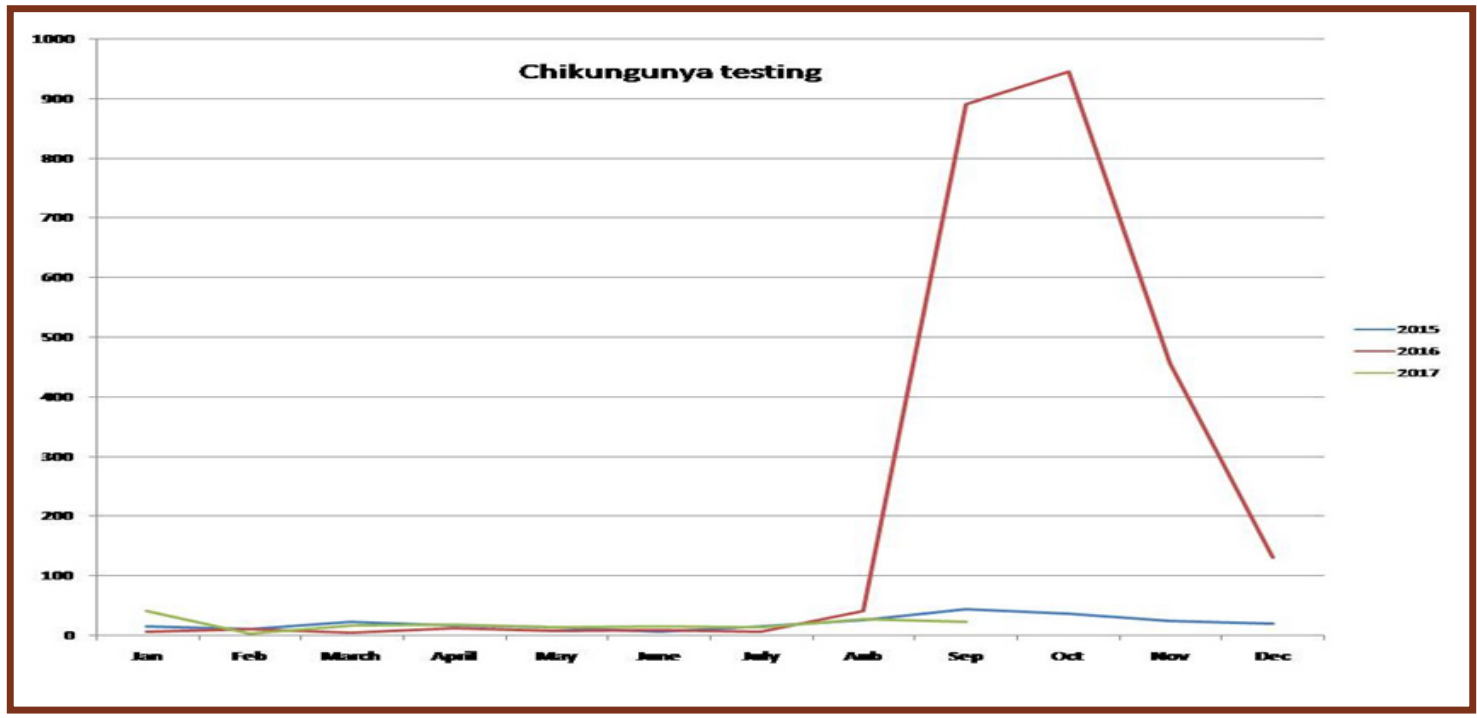

Fig. 6: Malaria testing yearly trend .

\section{Discussion}

Mosquitoes and their associated impact on our health and economics have become an environmental health issue. There is absence of documented evidence about the full social costs of mosquito transmitted diseases as there is currently absence of economic rationale underlying existing resource allocation for intervention programmes. Our study reinforces the seasonal trends as reported in other studies with the peak of the number of tests in September and October i.e. post monsoon period. The monthly trends clearly reflect the increased workload on diagnostic facilities in post monsoon period which calls for attention as the diagnostic centers and laboratories need to gear up in terms of manpower and resources so that they can cope up with the demand. The year 2016 saw a steep increase in vector borne disease tests with all three malaria, dengue and chikungunya increasing rapidly, not only there was increase in the order of tests but also in percentage positivity compared to 2015 . The only exception being dengue which recorded lower percentage positivity $30.60 \%$ compared to $50.25 \%$ in 2015 . In the year 2017 , there is slight decrease in the test numbers and percentage positivity which might be attributed to late extended rainy season and partly due to awareness among public relating to hygiene and sanitation.

Malaria is one of the serious public health problems across globe amounting to 400-500 million cases and more than 
1 million malaria related deaths globally each year [14]. There are several factors responsible for resurgence of malaria including, growth of human population, change in land usage, changes in temperature, rainfall, humidity and immunity levels. In India more than 973 million persons are exposed to malaria and in 1998 an estimated 577,000 disability adjusted life years (DALYs) were lost due to malaria [15]. Similarly the arboviral diseases like chikungunya and dengue are also affected by climate change and have high propensity to occur in post rainy season. Chikungunya appeared in India in 1963 but it reemerged in 2005 and since then it has spread with more than a million cases reported $[1,16,17]$. As the activity, distribution of mosquito and its ability to transmit virus is highly dependent on temperature and precipitation, we observe continuous peak resurgence every year for these vector borne diseases8. Dengue too has been a significant health problem as there has been repeated outbreaks in India since 1960 [18].

Our study shows that not only physicians but also laboratory services should be prepared to accommodate rising work flow in months of increased demand, to provide quality hassle free services. In this three year study, there was a rapid increase in number of dengue cases was observed in 2016 compared to the previous two years. The maximum number of dengue cases was seen in the month of September (Fig-5) indicative of an active viral transmission during monsoon and post-monsoon period, this finding was similar to other studies by Gupta $\mathrm{E}$ et al [19] and Ukey PM et al [20].

Our study depicts the seasonal variation in workload of three tests conducted by clinical laboratory. These tests for vector borne disease follow a seasonal pattern with increased work starting from August and reaching peak by mid September- early October and then declining by mid November. The laboratory staffing has a direct relationship on patient outcome and error rates in laboratory [21]. Our findings along with other published work in literature should provide evidence based information to enable directors of clinical laboratories in making objective decisions on restructuring the workforce. In a developing country like India where economic constraints prevail and laboratories generally suffer from budget cuts there is need for objective decisions so as to maintain the delivery of quality laboratory services throughout year. The workload trend emphasize the need of optimized staffing, right staff with right skills, in the right place and at the right time.

\section{Conclusion}

We have made an attempt to describe major seasonal vector borne disease and more studies are required for evaluation of factors related to seasonal variations. There is need of more public awareness campaigns, role of print media, electronic media and other means to inculcate value of sanitation, hygiene and cleanliness in order to restraint the spread of seasonal illness.

\section{Reference}

1. Quigley MA. Shifting burden of disease-epidemiological transition in India. Int J Epidemiol. 2006; 35:1530-1. PubMed

2. NCMH background papers - burden of disease in India. New Delhi: National Commission on Macroeconomics and Health \& Family Welfare, Ministry of Health, Government of India; 2005. Disease burden in India: estimations and causal analysis.

3. Snow RW, Guerra CA, Noor AM, Myint HY, Hay SI. The global distribution of clinical episodes of Plasmodium falciparum malaria. Nature. 2005;43 (4):214-7.

4. WHO. World Malaria Report 2014. WHO, Geneva. 2014. Available at http://apps.who.int/ iris/ bitstream/ 10665/144852/2/9789241564830_eng.pdf

5. India, Ministry of Health and Family Welfare. Malaria: magnitude of the problem. New Delhi: National Vector Borne Disease Control Programme, Directorate General of Health Services. http://www.nvbdcp.gov.in/malaria3.html accessed 27 September 2017.

6. WHO. Comprehensive Guidelines for Prevention and Control of Dengue and Dengue Haemorrhagic Fever (2011) Available: http://apps.searo.who.int/pds_docs/B4751.pdf. Accessed 20 Mar 2016.

7. Gubler DJ. Dengue and dengue hemorrhagic fever. Clin Microbiol Rev. 1998; 11:480-96.

8. Morin CW, Comrie AC, Ernst K. Climate and dengue transmission: evidence and implications. Environ Health Perspect. 2013; 121:1264-72.

9. Colón-González FJ, Fezzi C, Lake IR, Hunter PR. The effects of weather and climate change on dengue. PLoS Negl Trop Dis. 2013; 7:e2503.

10. Chowell G, Sanchez F. Climate-based descriptive models of dengue fever: the 2002 epidemic in Colima, Mexico. J Environ Health. 2006; 68:40-4.

11. Rosa-Freitas MG, Schreiber KV, Tsouris P, ETdS W, Luitgards-Moura JF. Associations between dengue and combinations of weather factors in a city in the Brazilian Amazon. Rev Panam Salud Publica. 2006; 20:256-67.

12. Shandera WX, Roig IL. Viral and rickettsial infections. In: Papadakis MA, McPhee SJ, Rabow MW (Eds). 2013: Current Medical Diagnosis and Treatment, 52nd edn. New 
York, NY: McGraw-Hill, 2013. pp. 1350-418.

13. Kalantri SP, Joshi R, Riley LW. Chikungunya epidemic: an Indian perspective. Natl Med J India 2006; 19(6):315-22.

14. Intergovernmental Panel on Climate Change (IPCC). Climate change 2001: The scientific basis. Contribution of Working Group I to the Third Assessment Report of the Intergovernmental Panel on Climate Change. Houghton JT, Ding Y, Griggs DJ, Noguer M, van der Linden PJ, Dai $\mathrm{X}$, Maskell K, Johnson CA, editors. Cambridge University Press, Cambridge, United Kingdom; 2001. p. 881.

15. Garg A, Dhiman RC, Bhattacharya S, Shukla PR. Development, malaria and adaptation to climate change: A case study from India. Environ Manage 2009; 43: 779-89.

16. Mavalankar D, Shastri P, Raman P. Chikungunya epidemic in India: a major public-health disaster. Lancet Infect Dis 2007; 7: 306-7.
17. Majra JP, Gur A. Climate change and health: Why should India is concerned? Indian J Occup Environ Med 2009; 13: 11-6.

18. Gage KL, Burkot T, Eisen RJ, Hayes N. Climate and vector borne diseases. Am J Prev Med 2008; 35: 436-450.

19. Gupta E, Dar L, Narang P, Srivastava VK, Broor S. Serodiagnosis of dengue during an outbreak at a tertiary care hospital in Delhi. Indian J Med Res 2005; 121: 36-8.

20. Ukey PM, Bondade SA, Paunipagar PV, Powar RM, Akulwar SL. Study of seroprevalence of dengue fever in central India. Indian J Community Med 2010; 35 : 517-9

21. McGahan M, Kucharski G, Coyer F. Winner ACCCN Best Nursing Review Paper 2011 sponsored by Elsevier. Nurse staffing levels and the incidence of mortality and morbidity in the adult intensive care unit: a literature review. Aust Crit Care. 2012; 25(2):64-77.1

*Corresponding author:

Dr. Rateesh Sareen, Consultant Pathology, Department of Pathology, Santokba Durlabhji Memorial Hospital \& Research center, Jaipur, India

Email: drrateeshsareen@yahoo.co.in 